\title{
Varafolkloorsetelt vokaalzhanridelt lauluni II
}

Noodinäited, indeks

\section{Hüüded ja hõiked}

Näide 1. RKM, Mgn. II 4029 (10) < Kihnu, Linaküla - I. Rüütel, A. Vissel < Virve Köster, 59 a (1987). Noodistanud I. Rüütel ja E. Tuvi, redigeerinud E. Tuvi.

Näide 2. RKM, Mgn. II 1576 b < Kihnu $<$ lindistatud Tallinnas - O. Kõiva ja A.

Strutzkin $<$ Theodor Saar, 62 a jt (1968). Noodistanud I. Rüütel ja E. Tuvi, redigeerinud E. Tuvi.

Näide 3. EÜS III $38(30)<$ Tartu $<$ Peeter Kurg ja Bruns (1906)

\section{Loodushäälendid ja looduskõnelused}

Näide 4. RKM, Mgn. II 3311 (11) < Häädemeeste < lindistatud Tartus - O. Kõiva, M Jallai < Marta Mäesalu, s. 1893 (1979). Noodistanud I. Rüütel ja E. Tuvi, redigeerinud E. Tuvi.

Näide 5. RKM, Mgn. II 3311 (15) < Häädemeeste < lindistatud Tartus - O. Kõiva, H. Silvet < Marta Mäesalu, s. 1893 (1979). Noodistanud I. Rüütel ja E. Tuvi, redigeerinud E. Tuvi.

Näide 6. RKM, Mgn. II 3311 (18) < Häädemeeste < lindistatud Tartus - O. Kõiva, H. Silvet < Marta Mäesalu, s. 1893 (1979). Noodistanud I. Rüütel ja E. Tuvi, redigeerinud E. Tuvi.

Näide 7. RKM, Mgn. II 3311 (19) < Häädemeeste < lindistatud Tartus - O. Kõiva, H. Silvet < Marta Mäesalu, s. 1893 (1979). Noodistanud I. Rüütel ja E. Tuvi, redigeerinud E. Tuvi.

Näide 8. RKM, Mgn. II 3311 (21) < Häädemeeste < lindistatud Tartus - O. Kõiva, H. Silvet < Marta Mäesalu, s. 1893 (1979). Noodistanud I. Rüütel ja E. Tuvi, redigeerinud E. Tuvi.

Näide 9. RKM, Mgn. II 3087 (1) < Simuna khk, Rahkla k - E. Liiv, I. Rüütel < Elfriide Tooming, 75 a (1978). Noodistanud I. Rüütel ja E. Tuvi, redigeerinud E. Tuvi.

Näide 10. RKM, Mgn. II 3311 (36) < Häädemeeste < lindistatud Tartus - O. Kõiva, H. Silvet < Marta Mäesalu, s. 1893 (1979). Noodistanud I. Rüütel ja E. Tuvi, redigeerinud E. Tuvi.

Näide 11. RKM, Mgn. II 3311 (13) < Häädemeeste < lindistatud Tartus - O. Kõiva, H. Silvet < Marta Mäesalu, s. 1893 (1979). Noodistanud I. Rüütel ja E. Tuvi, redigeerinud E. Tuvi.

Näide 12. RKM, Mgn. II 3311 (14) < Häädemeeste < lindistatud Tartus - O. Kõiva, H. Silvet < Marta Mäesalu, s. 1893 (1979). Noodistanud I. Rüütel ja E. Tuvi, redigeerinud E. Tuvi.

Näide 13. RKM, Mgn. II 3311 (12) < Häädemeeste < lindistatud Tartus - O. Kõiva, M. Jallai < Marta Mäesalu, s. 1893 (1979). Noodistanud I. Rüütel ja E. Tuvi, redigeerinud E. Tuvi. 
Näide 14. RKM, Mgn. II 3311 (25) < Häädemeeste < lindistatud Tartus - O. Kõiva, H. Silvet < Marta Mäesalu, s. 1893 (1979). Noodistanud I. Rüütel ja E. Tuvi, redigeerinud E. Tuvi.

Näide 15. RKM, Mgn. II 3311 (26) < Häädemeeste < lindistatud Tartus - O. Kõiva, H. Silvet < Marta Mäesalu, s. 1893 (1979). Noodistanud I. Rüütel ja E. Tuvi, redigeerinud E. Tuvi.

Näide 16. RKM, Mgn. II 3311 (27) < Häädemeeste < lindistatud Tartus - O. Kõiva, H. Silvet < Marta Mäesalu, s. 1893 (1979). Noodistanud I. Rüütel ja E. Tuvi, redigeerinud E. Tuvi.

Näide 17. RKM, Mgn. II 3311 (20) < Häädemeeste < lindistatud Tartus - O. Kõiva, H. Silvet < Marta Mäesalu, s. 1893 (1979). Noodistanud I. Rüütel ja E. Tuvi, redigeerinud E. Tuvi.

Näide 18. RKM, Mgn. II 1355 g < Sangaste khk, Kurevere k - O. Kõiva, I. Rüütel < Anton Tuisk, 60 a (1967). Noodistanud I. Rüütel ja E. Tuvi, redigeerinud E. Tuvi.

\section{Loitsud}

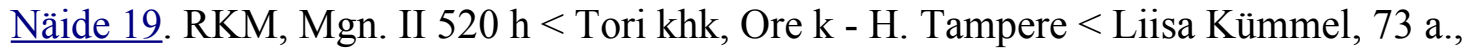
(1961). Noodistanud I. Rüütel ja E. Tuvi, redigeerinud E. Tuvi.

Näide 20. RKM, Mgn. II 45 c < Kihnu, Linaküla - O. Kõiva < Theodor Saar, s 1906 (1956). Noodistanud I. Rüütel ja E. Tuvi, redigeerinud E. Tuvi.

Näide 21. RKM, Mgn. II 1354 c < Sangaste khk, Kurevere k - O. Kõiva, I. Rüütel < Alma Taldrek, 55a (1967). Noodistanud I. Rüütel ja E. Tuvi, redigeerinud E. Tuvi. Näide 22. RKM, Mgn. II 1361 c < Sangaste khk, Restu k - O. Kõiva, I. Rüütel < Olga Rääk, 61 a (1967). Noodistanud I. Rüütel ja E. Tuvi, redigeerinud E. Tuvi.

Näide 23. RKM, Mgn. II 164 h < Setu, Mikitamäe k - V. Pino ja H. Tampere < Ida Pino, 64 a (1959). Noodistanud I. Rüütel ja E. Tuvi, redigeerinud E. Tuvi.

Näide 24. RKM, Mgn. II 1876 c < Vastseliina khk, Rebasmäe k - I. Rüütel < Liine Sillat, 90 a (1970). Noodistanud I. Rüütel ja E. Tuvi, redigeerinud E. Tuvi.

Näide 25. RKM, Mgn. II 1453 a, b < Kirbla khk, Säira k - R. Praakli ja I. Rüütel < Liisu Reinberg, 83 a (1968). Noodistanud I. Rüütel ja E. Tuvi, redigeerinud E. Tuvi.

Näide 26. RKM, Mgn. II 3088 (28) < Simuna khk, Rahkla k - E. Liiv, I. Rüütel < Emilie Senkel, 79 a (1978). Noodistanud I. Rüütel ja E. Tuvi, redigeerinud E. Tuvi. Näide 27. RKM, Mgn. II 3087 (18) < Simuna khk, Rahkla k - E. Liiv, I. Rüütel < Elfriide Tooming, 75 a (1978). Noodistanud I. Rüütel ja E. Tuvi, redigeerinud E. Tuvi. Näide 28. RKM, Mgn. II 43 a $<$ Kihnu, Turuküla - O Niinemägi (Kõiva) < Olga Türk, s. 1893 (1956). Noodistanud I. Rüütel ja E. Tuvi, redigeerinud E. Tuvi.

Näide 29. RKM, Mgn. II 520 i < Tori khk, Ore k - H. Tampere < Liisa Kümmel, 73 a (1961). Noodistanud I. Rüütel ja E. Tuvi, redigeerinud E. Tuvi.

Näide 30. RKM, Mgn. II 1361 d < Sangaste khk, Restu k - O. Kõiva, I. Rüütel < Olga Rääk, 61 a (1967). Noodistanud I. Rüütel ja E. Tuvi, redigeerinud E. Tuvi. Näide 31 . RKM, Mgn. II $520 \mathrm{j}<$ Tori khk, Ore k - H. Tampere < Liisa Kümmel, 73 a (1961). Noodistanud I. Rüütel ja E. Tuvi, redigeerinud E. Tuvi.

Näide 32. RKM, Mgn. II 1361 b < Sangaste khk, Restu k - O. Kõiva, I. Rüütel < Olga Rääk, 61 a (1967). Noodistanud I. Rüütel ja E. Tuvi, redigeerinud E. Tuvi. Näide 33. RKM II 43, 407/8 (1) < Tartu 1. < Halliste khk, Uue-Kariste v - Selma Lätt < Liisa Kutti, 78 a (1955). Noodistanud I. Rüütel ja E. Tuvi, redigeerinud E. Tuvi. 
Näide 34. RKM, Mgn. II 1453 I < Kirbla khk, Säira k - R. Praakli ja I. Rüütel < Liisu Reinberg, 83 (1968). Noodistanud I. Rüütel ja E. Tuvi, redigeerinud E. Tuvi.

\section{Lastelaulud}

Näide 35. RKM, Mgn. II 4007 (9) < Kihnu, Linaküla - I. Rüütel, A. Vissel < Anna Türk, 84 a (1986). Noodistanud I. Rüütel ja E. Tuvi, redigeerinud E. Tuvi.

Näide 36. RKM, Mgn. II 4007 (14) < Kihnu, Linaküla - I. Rüütel, A. Vissel < Anna

Türk, 84 a (1986). Noodistanud I. Rüütel ja E. Tuvi, redigeerinud E. Tuvi.

Näide 37. RKM, Mgn. II 3088 (23) < Simuna khk, Rahkla k - E. Liiv, I. Rüütel <

Helene Jõgimaa, 73 a (1978). Noodistanud I. Rüütel ja E. Tuvi, redigeerinud E. Tuvi.

Näide 38. RKM, Mgn. II $307 \mathrm{~g}<$ Häädemeeste khk, Muhu k - H. ja E. Tampere < Liidia Strandson, s 1896 (1959). Noodistanud I. Rüütel ja E. Tuvi, redigeerinud E. Tuvi.

Näide 39. RKM, Mgn. II 45 e $<$ Kihnu, Linaküla - O. Niinemägi (Kõiva) $<$ Theodor

Saar, s 1906 (1956). Noodistanud I. Rüütel ja E. Tuvi, redigeerinud E. Tuvi.

Näide 40. RKM, Mgn. II 445 a $<$ Tartu $1<$ Kambja khk - I. Rüütel $<$ Helene Kaseleht, 72 a (1961). Noodistanud I. Rüütel ja E. Tuvi, redigeerinud E. Tuvi.

Näide 41. RKM, Mgn. II 1223 d < Räpina khk, Jõepera k - I. Rüütel < Hele Harring, s 1900 (1966). Noodistanud I. Rüütel ja E. Tuvi, redigeerinud E. Tuvi.

Näide 42. RKM, Mgn. II 1223 e < Räpina khk, Jõepera k - I. Rüütel < Hele Harring, s 1900 (1966). Noodistanud I. Rüütel ja E. Tuvi, redigeerinud E. Tuvi.

Näide 43. RKM, Mgn. II 1356 a < Sangaste khk, Restu k - O. Kõiva, I. Rüütel < Alide

Parts, 67 a (1967). Noodistanud I. Rüütel ja E. Tuvi, redigeerinud E. Tuvi.

Näide 44. RKM, Mgn. II 445 b: Helene Kaseleht, 72 a., Tartu 1. (Kambja khk. - I.

Rüütel 1961. Noodistanud I. Rüütel ja E. Tuvi, redigeerinud E. Tuvi.

Näide 45. RKM, Mgn. II 164 a < Setu, Mikitamäe v, Usenitsa k - V. Pino ja H. Tampere $<$ Ida Pino, 64 a (1959). Noodistanud I. Rüütel ja E. Tuvi, redigeerinud E. Tuvi.

Näide 46. RKM, Mgn. II 3311 (3) < Häädemeeste < lindistatud Tartus - O. Kõiva, M

Jallai < Marta Mäesalu, s 1893 (1979). Noodistanud I. Rüütel ja E. Tuvi, redigeerinud

E. Tuvi.

Näide 47. RKM, Mgn. II 4007 (6) < Kihnu, Linaküla - I. Rüütel, A. Vissel < Anna

Türk, 84 a (1986). Noodistanud I. Rüütel ja E. Tuvi, redigeerinud E. Tuvi.

Näide 48. RKM, Mgn. II 3087 (26) < Simuna khk, Rahkla k - E. Liiv, I. Rüütel <

Elfriide Tooming, 75 a (1978). Noodistanud I. Rüütel ja E. Tuvi, redigeerinud E. Tuvi.

Näide 49. RKM, Mgn. II 3311 (22) < Häädemeeste < lindistatud Tartus - O. Kõiva, H.

Silvet < Marta Mäesalu, s 1893 (1979). Noodistanud I. Rüütel ja E. Tuvi, redigeerinud

E. Tuvi.

Näide 50. RKM, Mgn. II 445 d $<$ Tartu 1. < Kambja khk - I. Rüütel < Helene Kaseleht, 72 a (1961). Noodistanud I. Rüütel ja E. Tuvi, redigeerinud E. Tuvi.

Näide 51. EFA I 32, $54<$ Pärnu - I. Rüütel < oma mälu järgi, käibel laste seas Pärnus u 1945-1954. Noodistanud I. Rüütel ja E. Tuvi, redigeerinud E. Tuvi.

Näide 52. EFA I 32, $54<$ Tartu $<$ I. Rüütel $<$ oma mälu järgi, vanaemalt. Noodistanud I.

Rüütel ja E. Tuvi, redigeerinud E. Tuvi. 


\section{Ahel- ja kumulatiivsed laulud}

Näide 53. RKM, Mgn. II 164 d < Setu, Mikitamäe v, Usenitsa k - V. Pino ja H.

Tampere < Ida Pino, 64 a (1959). Noodistanud I. Rüütel ja E. Tuvi, redigeerinud E. Tuvi.

Näide 54. RKM, Mgn. II 445 e $<$ Tartu $1<$ Kambja khk - I. Rüütel $<$ Helene Kaseleht, 72 a (1961). Noodistanud I. Rüütel ja E. Tuvi, redigeerinud E. Tuvi.

Näide 55. RKM, Mgn. II 1356 b < Sangaste khk, Restu k - O. Kõiva, I. Rüütel < Alide Parts, 67 a (1967). Noodistanud I. Rüütel ja E. Tuvi, redigeerinud E. Tuvi.

Näide 56. EÜS VIII $2535(170)<$ Kuusalu khk, Hara k - K. Viljak, G. Vilberg < Gustav Eistruk, u 60 a (1911) (H. Tampere Eesti rahvalaule viisidega. Tallinn 1958, 1k 210211).

\section{Laulud muinasjuttudes}

Näide 57. RKM, Mgn II 1766 a < Suure-Jaani khk, Epra k - I. Rüütel, O. Kõiva (1970). Noodistanud I. Rüütel ja E. Tuvi, redigeerinud E. Tuvi.

Näide 58. K. Salve \& V. Sarv. Setu lauludega muinasjutud. Tallinn 1987, 1k 161, nr 27; Vaeslaps käoks.

\section{Itkud}

Näide 59. V. Pino \& V. Sarv. Setu surnuitkud II. Tallinn 1982, nr 57; Itk õele (RKM, Mgn. II 3317 (2) < Setu, Pööni k. - Õ. Sarv < Pelageja Karulaan, s. 1906. (1980).

Näide 60. I. Rüütel (koost, toim). Ida-Virumaa rahvakultuurist. Tallinn 1992, 1k. 253 (RKM II 68, 13/3 (3) < Tallinn < Narva - I. Rüütel < Lisette Siirak. 59 a (1959) Itk mehele).

Näide 61. RKM, Mgn II 1428 f < Hanila khk - H. Tampere, O. Kõiva < Mari Luik, s 1884 (1984).

\section{Mõistatused}

Näide 62. RKM, Mgn II $1611 \mathrm{f}<$ Kuusalu khk, Tapurla k - I. Rüütel, O. Kõiva < Risanda Kravtsov, 60 a (1969). Noodistanud I. Rüütel ja E. Tuvi, redigeerinud E. Tuvi. 